\title{
OFICINA DE VIVÊNCIA CORPORAL: MOVIMENTO, REFLEXÃO E APROPRIAÇÃO DE SI MESMO
}

\author{
CORPORAL EXPERIENCE WORSHOP: MOVEMENT, REFLECTION AND SELF \\ APPROPRIATION
}

\author{
TALLER DE VIVENCIA CORPORAL: MOVIMIENTO, REFLEXIÓN Y \\ APROPRIACIÓN DE SI MISMO
}

\author{
José Roberto da Silva Brêtas* \\ Filadelfo Queiroz Santos**
}

Brêtas JRS, Santos FQ. Oficina de vivência corporal: movimento, reflexão e apropriação de si mesmo. Rev Esc Enferm USP 2001; 35(3):242-8.

\section{RESUMO}

O presente artigo aborda uma atividade inovadora no campo de ensino na área de Enfermagem. Esta atividade, teórica vivencial, que chamamos de "Oficina de vivência corporal", tem como propostas: promover a consciência corporal; a apreensão de fundamentos sobre corporalidade; e fomentar a reflexão sobre si e o corpo do "outro ", que é sujeito de cuidados em enfermagem. É desenvolvido com alunos do Primeiro ano do Curso de Graduação em Enfermagem - Universidade Federal de São Paulo - UNIFESPI EPM. Apresenta uma pesquisa descritiva, onde o fenômeno é descrito e explicado . Propõe-se investigar aspectos relativos a experiência de 202 alunos que participaram das atividades desenvolvidas nas oficinas, durante os anos de 1997, 1998 e 1999.

PALAVRAS-CHAVE: Cuidado de enfermagem. Enfermagem. Imagem corporal.

\begin{abstract}
The present study approaches an innovative activity in the Nursing teaching area. This activity, theoretical-experiential, known as the "Corporal Experience Workshop" is intended to promote body awareness, understand the fundamentals related to corporality, and improve the reflections about the own self and the "other's" body when undergoing nursing care. The investigation was carried out with first grade undergraduation Nursing students of the Universidade Federal de São Paulo - UNIFESP/EPM, and presents a descriptive study where the phenomenon is described and explained, and at the same time, it seeks to investigate some aspects concerning experiences the participating 202 students were submitted to during the activities developed in the workshops, during in the yaers 1997, 1998 and 1999.
\end{abstract}

KEYWORDS: Nursing care. Nursing. Body imagem.

\section{RESUMEN}

El presente articulo aborda una actividad inovadora en el campo de ensenanza en la área de Enfermeria. Esta actividad, teórica-vivencial, que llamamos de "Taller del Vivencia Corporal", tiene como propuestas: promover la consciencia corporal; la aprehensión de fundamentos sobre corporalidades; e incentivar la reflexión sobre uno y el cuerpo del "outro" que es sujeto de cuidados en Enfermeria. Es desarrollado com alumnos del Primer ano del Curso de Graduación en Enfermeria Universidad Federal de São Paulo - UNIFESP/EPM. Presenta una encuesta descriptiva adonde el fenómeno es descripto y explicado. Proponese averiguar aspectos relativos a las experiencias de 202 alumnos que participaran de las actividades desarrolladas en los talleres durante anos de 1997, 1998 y 1999.

PALABRAS-CLAVE: Atención de enfermeria. Enfermerla. Imagen corporal.

\footnotetext{
Enfermeiro, Psicólogo Clínico, Psicomotricista, Psicossomatista, Professor Assistente do Departamento de Enfermagem da Universidade Federal de São Paulo - UNIFESP/EPM.

** Enfermeiro, Psicólogo Clínico e Hospitalar, Especialista em Enfermagem de Saúde Mental e Psiquiátrica, Mestre em Enfermagem, Técnico Administrativo do Departamento de Enfermagem da Universidade Federal de São Paulo UNIFESP/EPM.
} 


\section{INTRODUÇÃO}

A "Psicologia Aplicada à Saúde", disciplina curricular, ministrada a alunos do Primeiro ano do Curso de Graduação em Enfermagem da Universidade Federal de São Paulo - UNIFESP/ EPM, visando atender as necessidades do novo currículo em processo de implantação e ao movimento trans - disciplinar que ocorria, propôs uma atividade inovadora no campo de ensino em Enfermagem. Esta atividade, teórica vivencial, que chamamos de "Oficina de Vivência Corporal", tem como proposta: promover a consciência corporal, a apreensão de fundamentos sobre corporalidade e fomentar reflexão sobre si e o corpo do "outro" que é sujeito dos cuidados de enfermagem.>

$\mathrm{O}$ termo corporalidade significa qualidade corpórea, designa o conjunto complexo, porém unitário das maneiras de ter e de ser um corpo que nem sempre é aquele percebido pelo outro.

$\mathrm{O}$ insight para elaboração e desenvolvimento deste trabalho, teve como fator desencadeador a função essencial da Enfermagem: o cuidar; que é o momento específico da(o) profissional enfermeira(o), considerado por muitos a essência do existir da profissão e do ser enfermeira(o) enquanto profissional.

O cuidar constitui-se no mais poderoso símbolo da enfermagem; confunde-se com ela; representa-a. Galga patamares superiores, quer no plano moral (zelo), quer no tecnológico, saindo da marginalidade como ato de menor valor, para regular-se, hoje, tal qual a necessidade humana fundamental à própria sobrevivência de individuos(1).

$O$ cuidar envolve verdadeiramente uma ação interativa. $\mathrm{O}$ processo de cuidar é aqui definido como o desenvolvimento de ações, atitudes e comportamentos com base em conhecimento científico, experiência, intuição e pensamento crítico realizadas para e com o paciente cuidado no sentido de promover, manter el ou recuperar sua dignidade e totalidades humanas. Essa dignidade e totalidade englobam o sentido de integridade e a plenitude física, social, emocional, espiritual e intelectual nas fases do viver e do morrer e constitui, em última análise, um processo de transformação de ambos, cuidadora e ser cuidado(2).

O Processo de Enfermagem foi definido como sendo as interações entre a (o) enfermeira (o) e paciente. Essas interações fundamentam-se nos elementos do "Processo de Cuidar" e têm como objetivo atender as necessidades de cuidado do cliente. Ainda afirma que cuidado prestado, pela (o) enfermeira (o) ao paciente, é efetuado a partir de uma praxis, constituída por um conjunto de técnicas descritas como procedimentos de enfermagem, que pode ser um procedimento realizado com o paciente (banho no leito, curativos, sondagens, instilações, administração de medicamentos, mudança de decúbito no leito e outros) (3).
Embora o ato de cuidar pareça teoricamente simples e às vezes, realizado de forma mecânica, este conjunto de ações traduzem a forma e o movimento de uma expressão corporal que revela a natureza de uma existência.

As (os) alunas (os) são treinadas (os) para desenvolver uma relação com o paciente dentro dos modelos descritos nos livros de enfermagem. Só que estes modelos não dão conta do lado emocional da relação, principalmente aos aspectos relativos à corporalidade.

A comunicação enfermeira (o)/ paciente transcende o verbal. A partir do toque que é constante nos procedimentos do cuidado, a expressividade corporal ganha uma importância singular.

que somos e transmitimos quando usamos nossas defesas e nos exprimimos através da palavra nem sempre é verdadeiro, mas quando tocamos alguém além de transmitirmos aquilo que desejamos transmitir, mostramos nosso estado interno.

A linguagem dos sentidos, na qual podemos ser todos socializados, é capaz de ampliar nossa valorização do outro e do mundo em que vivemos e de aprofundar nossa compreensão em relação a ele. Tocar é a principal dessas outras linguagens. As comunicações que transmitimos por meio do toque constituem o mais profundo meio de criar relacionamentos humanos, como fundamento da experiência (4).

Neste contexto, o corpo é nosso objeto de atenção. Temos como referência um pressuposto importante na Psicologia do Corpo, onde se afirma que: meu corpo sou eu. O corpo que você tem é o corpo que você vive. Nosso sentimento e nossa capacidade de resposta moldam nossas vidas. Formamos nosso self corporal ao mesmo tempo em que moldamos a nossa própria realidade. Nosso viver corporal molda a nossa existência. (5).

Entendemos que o corpo é um processo e produto final de experiências agradáveis e desagradáveis, que cristalizam o psíquico, protege-o como uma armadura tônica específica e dá alicerce ao seu Eu. E um instrumento de realização e criação, centro difusor de satisfação e de dor, base da organização perceptiva e cognitiva; o corpo se emancipa como ponto de referência espacial e existencial e transforma-se em um substrato da personalidade.

O corpo está envolvido nas emoções que produz. As emoções são um primeiro sistema de comunicação, traduzem rupturas e ligações com o meio humano e fisico. Sensibilidades, sensorialidades, motricidade e sensualidade se misturam constantemente. As emoções com seus cortejos psico-fisicos e corporais constituem linguagens corporais privilegiadas; primitivas talvez, mas sempre presente em cada um de nós.

Trabalhar com a consciência da percepção do corpo de quem cuida do outro é ampliar o conhecimento sobre o seu conjunto de expressões, sobre aquilo que é revelado aos pacientes pela (o) aluna (o) de Enfermagem. 
Por se tratar da formação de um profissional que cuida do corpo do outro, que tem como princípio o cuidado integral ao indivíduo, sem esquartejá-lo em segmentos de carne, como ocorre no modelo médico assistencial, em um processo de super - especialização, foi proposto um movimento antagônico ao pensamento cartesiano, pois o corpo é receptor e emissor de tudo, onde mente e corpo são uno. A consciência que temos de ser é criada a partir das condições trazidas pela inserção da mente numa corporalidade. Assim, a finalidade dessa atividade resume-se em um processo de autoconhecimento e de fornecer subsídios para que a (o) aluna (o) de Enfermagem cuide melhor de si e do corpo do outro.

Esta vivência propiciada aos alunos oferece a cada um a possibilidade de descobrir dentro de si mesmo, na sua própria experiência corporal, a verdadeira consciência das sensacões. Para tanto, a metodologia utilizada é prática e vivencial, constituída por técnicas corporais adotadas com caráter pedagógico.

As técnicas utilizadas nesse processo são: Eutonia e o Treinamento Autógeno, as quais proporcionam vivências nos campos da percepção de espaço interno; da tridimensionalidade do corpo, seu volume, a consciência dos ossos, articulações, músculos, tônus e superfície da pele; do movimento e espaço habitado; além de relações interpessoais.

Trata-se de um trabalho com enfoque anatômico. Com relação a este enfoque, encontramos a referência de que sem anatomia não há emoções e que os sentimentos têm uma arquitetura somática (6).

A Eutonia propõe uma busca, adaptada ao mundo ocidental, para ajudar o indivíduo de nosso tempo a alcançar uma consciência mais profunda de sua realidade corporal e espiritual, como uma verdadeira unidade ${ }^{(7)}$. Em outras palavras, a Eutonia convida o indivíduo a aprofundar-se na descoberta de si mesmo, sem se retirar do mundo, mas ampliando sua consciência cotidiana, permitindo-lhe a liberação das forças criadoras, um melhor ajustamento às situações de vida e um enriquecimento permanente da personalidade e da realidade social.

A palavra Eutonia (do grupo Eu que significa bom, justo, harmonioso, tonos igual a tônus e tensão) foi criada em 1957 para expressar a idéia de umatonicidade harmoniosamente equilibrada, em adaptação constante, ajustada ao estado ou à atividade do momento (7)

A Eutonia é tanto uma abordagem somatopsiquica como uma perspectiva psicossomática, pois ambas sustentam que experiências psicológicas e/ou fisicas ficam impressas na estrutura e na memória do corpo. Essas experiências anteriores podem ser observadas nas posturas, gestos e diversos movimentos, afetando toda a vida da pessoa (8).
A proposta eutônica é explorar, tomar consciência, aguçando e concentrando a atenção nas sensações obtidas nas diferentes regiões do corpo.

O Treinamento Autógeno de Schultz traduz-se em um exercício psicoplásico* de atitudes expectantes, ritualístico, escalonado, que faz com que fantasias positivas se transformem em realidades positivas. Tratase de relaxamento e auto-indução, a partir de um método psico-fisiológico, que segue uma orientação organísmica que escolhe como ponto de partida as reações do organismo vivente e não tanto as manifestações psíquicas da consciência, sem, porém, omiti-las (9)

A partir dessas técnicas corporais que promovem sensações e despertam reações, possibilitou-se aos participantes condições à percepção e à consciência corporal; formas de detectar e aliviar tensões a partir de eliminação das fixações tônicas; contato consigo próprio e com o mundo, além de descobertas pessoais a partir do contato com a realidade interior.

Com base nos pressupostos apresentados, propomos investigar alguns aspectos relativos às experiências das (os) alunas (os) que participaram das atividades desenvolvidas nas "Oficinas de Vivência corporal".

\section{OBJETIVO}

Identificar aspectos da experiência de alunos que freqüentaram as "Oficinas de Vivência Corporal" que contribuíram para sua vida pessoal e profissional.

\section{METODOLOGIA}

\section{Tipo e local de Pesquisa}

Trata-se de um estudo descritivo, em abordagem qualitativa, através do método de Análise de Conteúdo. A Análise de Conteúdo é um conjunto de técnicas de análise das comunicações". Esse conjunto de técnicas de análise das comunicações visa, através de procedimentos sistemáticos e objetivos de descrição do conteúdo das mensagens, obter indicadores, qualitativos ou não, que permitam a inferência de conhecimentos relativos às condições de produção/ recepção dessas mensagens. Trata-se de uma forma de categorização de dados verbais ou comportamentais, sendo o objeto da análise a mensagem contida nas comunicações orais ou escritas.

A Análise de Conteúdo visa tornar evidentes e significativamente plausíveis à corroboração lógica, os elementos ocultos da linguagem humana, além de descobrir o significado original dos seus elementos manifestos ${ }^{(1-12)}$.

\footnotetext{
* Potencialidade psicoplásica define-se como o esqueleto das disposições mentais congênitas, inalteráveis e permanentes do indivíduo (11).
} 
O presente estudo foi realizado com participantes das atividades desenvolvidas nas "Oficinas de Vivência Corporal", realizadas no Departamento de Enfermagem da UNIFESP/EPM, compreendendo os períodos letivos de 1997, 98 e 99.

\section{Sujeitos}

Participaram do estudo alunas (os) que freqüentaram as atividades desenvolvidas nos grupos das "Oficinas de Vivência Corporal", onde os critérios de inclusão foram: participação em todo o processo e ter concordado, de livre e espontânea vontade, em participar do estudo. As atividades foram organizadas em duas sessões com carga horária de 4 horas/aula cada. Os sujeitos que participaram desta pesquisa constituem uma população de 202 alunos do Primeiro ano do Curso de Graduação em Enfermagem.

\section{Aspectos Éticos}

Vale ressaltar que o projeto de pesquisa foi enviado, avaliado e aprovado pelo Comitê de Ética da Universidade Federal de São Paulo - UNIFESP. Uma vez que obtivemos a aprovação para realização da pesquisa, os sujeitos foram orientados e aceitaram participar da mesma. Desta forma, confirmamos que todos os procedimentos metodológicos obedeceram os padrões éticos estabelecidos pela Instituição.

\section{Forma de Coleta de Dados}

Para a coleta de dados, utilizou-se como instrumento a entrevista.

A opção pela entrevista enquanto instrumento, deve-se ao fato de que o mesmo possibilita uma atmosfera de interação e reciprocidade entre quem entrevista e o entrevistado. Nas entrevistas não totalmente estruturadas, onde não há a imposição de uma ordem rigida de questões, o entrevistado discorre sobre o tema proposto com base nas informações que ele detém e que no fundo são a verdadeira razão da entrevista. Na medida em que houver um clima de estimulo e de aceitação mútua, as informações fluirão de maneira notável e autêntica ${ }^{(13) .}$

Trata-se de uma conversa a dois, feita por iniciativa do entrevistador, destinada a fornecer informações pertinentes para uma objeto de pesquisa, e entrada (pelo entrevistador) em temas igualmente pertinentes com vistas a este objeto (14). Onde segundo a mesma autora, a grande vantagem da entrevista sobre as outras técnicas é que ela permite a captação imediata e corrente da informação desejada, praticamente com qualquer tipo de informante e sobre os mais variados tópicos. Quando a entrevista é bem sucedida pode permitir o tratamento de assuntos de natureza estritamente pessoal e intima, assim como temáticas de natureza complexa e de escolhas nitidamente individuais, o que permite um aprofundamento sobre o assunto pesquisado.
$\mathrm{Na}$ entrevista a relação que se cria é de interação, havendo uma atmosfera de influência recíproca entre quem pergunta e quem responde. Especialmente nas entrevistas não totalmente estruturadas, onde não há a imposição de uma ordem rígida de questões, o entrevistado discorre sobre o tema proposto com base nas informações que ele detém e que no fundo são a verdadeira razão da entrevista. Na medida em que houver um clima de estimulo e de aceitação mútua, as informações fluirão de maneira notável e autêntica. Permite a captação imediata e corrente da informação desejada, praticamente com qualquer tipo de informante e sobre os mais variados tópicos ${ }^{(13)}$

O primeiro passo foi elaborar uma proposição ou questão orientadora da investigação, que se constituiu de: Como foi a sua experiência na "Oficina de Vivência Corporal" ? A pesquisa se consistiu da aplicação dessa questão no final da vivência.

\section{Tratamento dos dados}

Na pesquisa descritiva os dados devem ser analisados e interpretados e podem ser qualitativos, utilizando-se de palauras para descrever o fenômeno, ou quantitativos, expressos mediante simbolos numéricos (15). Nesta pesquisa, optamos pela análise de conteúdo, que é um método de tratamento e análise de informações, colhidas por meio de técnicas de coleta de dados, consubstanciadas em um documento.

A técnica se aplica a análise de textos escritos ou de qualquer comunicação (oral, visual, gestual) reduzida a um texto ou documento(16).

Após a entrevista, realizou-se a análise dos dados fazendo uma leitura integral dos relatos de cada aluna (o), tentando compreender suas experiências. Foram lidos de tal forma a obter-se um sentido geral do todo de cada relato. Em seguida, realizamos uma releitura de cada relato, buscando o significado para a (o) aluna (o) da sua participação na atividade.

Os significados foram classificados e agrupados por suas semelhanças, dando origem as categorias a partir da análise das descrições das falas dos sujeitos. A categorização é uma operação de elementos construtivos de um conjunto, por diferenciação $e$, seguidamente, por reagrupamento o gênero (analogia), com os critérios previamente definidos. As categorias são rubricas ou classes, as quais reúnem um grupo de elementos sob um título genérico, agrupamento esse efetuado em razão dos caracteres comuns destes elementos ${ }^{(10)}$.

Do conjunto de técnicas da Análise de Conteúdo, optamos pela análise categorial, que funciona por operações de desmembramento do texto em unidades e em categorias segundo reagrupamentos analógicos. 


\section{ANÁLISE E DISCUSSÃO DOS DADOS}

Os dados obtidos através do recorte das percepções dos alunos que participaram dos grupos de vivências acerca de suas experiências, foram classificados e agregados em categorias como: autoconhecimento, expectativas, percepção corporal, aprendizagem, ambiente terapêutico, espaço interrelacional, sugestões e avaliação da vivência.

A categoria autoconhecimento nos mostra a contribuição da atividade para processos corporais pessoais, levando a (o) aluna (o) ao contato com ele mesmo, o que facilita o caminho para o autoconhecimento, conforme é destacado nas seguintes verbalizações:

"Se não vivenciamos as nossas próprias ações, como poderemos entender os outros".

"Foram momentos de autoconhecimento, foram instantes de emoções e de entrega do corpo às experiências ".

Em relação às expectativas, percebemos a existência de sentimentos nas (os) alunas (os) como: ansiedade, medo e curiosidade frente ao desconhecido. As frases a seguir expressam tais sentimentos acerca do momentos que antecederam as atividades na "Oficina de Vivencia Corporal":

"Eu pensei que fosse algo ligado ao teatro $e$ expressão corporal" .

"Vim para a oficina de vivência corporal curiosa".

"Quando eu cheguei, estava tensa".

"Estava com ansiedade".

"Estava com muitas expectativas ".

"Não tinha nenhuma idéia do que aconteceria".

Os elementos da categoria percepção corporal refletem a dificuldade na percepção do próprio corpo. Neste sentido, criamos espaço e condições para o exercício da somatognosia*, pela representação ativa e dinâmica do corpo no espaço, subentendo a postura, os seus segmentos corporais e o seu revestimento cutâneo, através dos quais a (o) aluna (o) se encontra em contato com o mundo envolvente. O que é evidenciado nas expressões:

"Descobri que tinha muitos pontos de tensão".

"Pude perceber aos poucos que estava tomando consciência do meu corpo, sensações que desconhecia ".

"Percebi que não conhecia o meu corpo e que isto é ruim, pois estava ignorando o principal para se viver plenamente".
"Aprendi vários movimentos com os braços,

pernas e quadril que propiciaram relaxamento ".

"Os exercícios utilizados ajudam a perceber

partes do meu corpo que antes nunca dei importância".

"Meu corpo parece que ficou mais leve e as

áreas nas quais eu sentia tensão ficaram relaxadas ".

"Percebi o relaxamento de cada músculo".

"Acho que me conheci um pouco mais".

"Possibilitou-me o conhecimento do corpo não

desvinculado de suas sensações".

"Pude perceber coisas, mudanças em meu corpo, que anteriormente passavam despercebidos. Tenho certeza de que a partir desta experiência percebi com mais sensibilidade, as reações de meu corpo, o que ele realmente quer e precisa para estar bem".

"Sinto meu corpo maltratado".

Esses conteúdos corroboram para a idéia que a relação que constituímos com o próprio corpo é importante, mas às vezes nos esquecemos deste fato. Entretanto não é igualmente claro o grau de envolvimento entre nossas presenças fisica, emocional e mental no mundo. Quando abordamos as complexas ligações o Eu e o ambiente, passamos inevitavelmente pelo corpo, por que ele é o meio através do qual e pelo qual tais relacionamentos podem ocorrer.

Neste sentido, o corpo é capaz de moldar suas próprias experiências. Podemos aprender com nosso processo corporal a formar nossas vidas continuamente e que vivemos mais de uma forma corporal ao longo da nossa vida. Quanto a esse fato, salientamos que a vida produz formas. Essas formas são partes de um processo de organização que dão corpo às emoções, pensamentos e experiências, fornecendolhes uma estrutura. Essa estrutura, por sua vez, ordena os eventos da existência (6).

Os exercícios foram efetuados com ajuda dos objetos ou através de massagens ou de mobilizações passivas. O aperfeiçoamento da percepção da realidade corporal permite uma certa segurança instintiva. Isso ajudou as (os) alunas (os) achar em seu corpo um aliado poderoso, um barômetro de suas necessidades. Isso lhe permitiu a distinção entre o que é essencial e o que é acessório, a fim de descobrir o que lhe faz bem. Não se trata de uma regressão a um estado primitivo de segurança instintiva, mas o esclarecimento, através de um trabalho pessoal de certas leis próprias ao organismo. Esses exercícios favorecem não só o aperfeiçoamento das percepções corporais, mas têm, também, como conseqüência a ampliação das zonas de troca com o meio que as (os) cercam, o que estimula a faculdade de adaptação e de

\footnotetext{
** A somatognosia compreende um modelo corporal plástico, com sigularidade própria e locomoção intra-individual intrínseca, com o qual nos reconhecemos no que somos, , um componente inseparável do psíquico, cujo substrato neurológico principal de integração, parece situar-se no córtex. Retrata o sentimento de corpo, uma atualizada memória de estados do corpo, desde a interoceptividade até a exteroceptividade, passando pela própria próprioceptividade. Enfim, a somatognosia reflete um estado corporal pessoal, fortalecendo a identidade do $\mathrm{Eu}^{(17)}$.
} 
reação aos acontecimentos. Pela distensão as (os) alunas (os) podem sentir seus corpos como uma unidade. Familiarizam-se com eles, os reconhecem progressivamente como um elemento constitutivo de suas personalidades e de suas identidades.

A tomada de consciência da realidade fisica do $E u$, através de exercícios simples, torna-se assim extremamente tranqüilizante.

Em se tratando da categoria aprendizagem, constatamos que esta forma de atividade corporal desenvolvida com os alunos, pode ajudá-los na aprendizagem de perceber e se perceber, a tomar consciência de suas necessidades, das tensões, posturas e reações diante de situações de estresse e, também, prepará-los para o autocuidado. As frases que ilustram está categoria é composta por:

"Já estou utilizando no hospital, fazendo em mim mesmo para aliviar o estresse".

"Na anatomia é tudo separado, aqui eu associei cada parte com o movimento ".

"Acho que vou começar a prestar mais atenção em mim mesma, tentar corrigir erros e diminuir o peso que a má postura e os maus costumes depositam sobre o meu corpo".

"Enriquecimento pessoal e até profissional".

"Foi muito construtivo".

"Antes não conhecia a minha tensão, agora sei, pego a bolinha de tênis quando tenho tempo e aplico em mim mesmo a massagem".

No que tange a categoria ambiente terapêutico, parece que conseguimos criar um espaço de confiança e seguro o suficiente para as autodescobertas, expressão das sensações, emoções e para o relaxamento das tensões. As frases extraidas dos depoimentos das (os) alunas (os) que indicaram a construção de uma ambiente terapêutico são:

"É um espaço que nos oferece a oportunidade da auto - descoberta".

"Acho essencial que os alunos tenham um espaço para que possam se curtir, se conhecer e mesmo aprender de uma forma diferente que a tradicional".

"E um espaço para serem colocados os sentimentos e as emoções ".

"Um espaço que precisava para renovar as energias, esquecer o tédio e o descaso dos professores das diversas disciplinas ".

"Procurei me desligar do mundo, esquecer as preocupações e acabei por sentir a mim mesma, perceber meu próprio eu".

"Meu corpo ficou mais leve e minha alma em paz".

"São aflorados sentimentos e emoções que constantemente busco reprimir, e esse esvaziar-me $e$ libertar-me trouxe-me uma serenidade sem igual".

"O dia parece ser mais produtivo, mais amplo e intenso".
"Relaxar o peso e o estresse que estavam sobrecarregando meu corpo ".

"A questão do relaxamento foi totalmente nova para mim, além de me fazer bem ".

"Esta vivência me trouxe paz, harmonia, compreensão e tranqüilidade".

"Momentos de muita paz interior".

"Foi uma sensação muita boa e relaxante".

"Sensação de angustia".

O espaço inter-relacional foi construído a partir da dinâmica de envolvimento e participação dos alunos nas sessões de vivência, o que possibilitou a troca de experiências, relações de troca, reflexão sobre o outro, melhor convivência e socialização do grupo. As frases que ilustram esta categoria são: receber".

"Na relação com as colegas, pude viver o dar e

"Gostei das práticas que nos fizeram tocar um no outro. Tenho dificuldades em tocar as pessoas $e$ achei que me soltei um pouco. Senti também maior proximidade de meu grupo e passamos a nos entender melhor".

"Momento de perceber a relação com o outro e como me posiciono nas relações de troca".

"Este perceber e esta atenção do que o outro sente é fundamental no desenvolver da nossa profissão, afinal os nossos objetos de trabalho são seres humanos que têm reações e sentimentos".

"É um espaço para conhecermos nosso corpo para melhor cuidarmos do corpo das outras pessoas ".

Isso demonstra que além do corpo pode-se de alguma maneira apresentar-se como uma prisão, pode também, oferecer-nos infinitas possibilidades de contato com o outro.

A vivência propiciou um canal para o exercício do processo de corporificação de experiências internas, que organiza a continuidade e confere significado emocional a nós e aos outros. E um padrão que tem a ver com ser capaz de dar e receber.

Constata-se, por fim, que as categorias sugestões e avaliação da vivência, sugerem que o trabalho alcançou seus objetivos junto aos discentes, no que tange sua importância enquanto atividade curricular, percepção de si e do outro, além de contribuir para a formação profissional.

As frases que ilustram a categoria sugestões são:

"Devia haver mais encontros".

"Gostaria que tivéssemos esta vivência todos os dias, não só na sexta-feira".

"Gostaria que mudasse o horário para tarde, por que depois iriamos para casa, sem precisar retornar a sala de aula".

"Deveria ser uma atividade curricular e estar em todas as séries". 
As frases que expressam as manifestações das (os) alunas (os) como uma avaliação da vivência são:

"Acredito que durante todo o ano, essa foi a experiência nova mais interessante pela qual passei, é muito legal entender o corpo de uma outra pessoa, mas descobrir o próprio é muito melhor".

"Foi uma experiência muito válida e agradável, poderia ser estendida a segunda série, uma vez ao mês. Pois faz um bem danado para cabeça, alma e para o corpo".

"Esses momentos nos fazem lembrar que nós também temos um corpo, e se não lembramos dele o trabalho com o outro fica prejudicado".

"Proporcionou-me um perfeito bem-estar físico".

"Em um momento de grandes preocupações, problemas e estresse que estou vivendo nesta fase da vida, pude por algumas horas desligar e relaxar, me sentir como uma criança sem preocupações, apenas me descobrindo ".

"Foi uma experiência muito importante".

"Foi uma experiência inovadora e produtiva". "A abordagem foi bem realizada com exercícios que trabalharam todas as partes do corpo".

"Ultrapassou as minhas expectativas ".

"O que me chamou a atenção foi que a vivência apresentou exercícios simples, podendo ser reproduzidos em casa diariamente".

"Após a experiência, acho que a carga horária deveria ser maior, quem sabe até persistir durante todo o curso de Enfermagem, mesmo que fosse de forma optativa".

"É importante não somente para nós alunos e futuros profissionais, mas para todos que desejam uma harmonia consigo mesmo".

Através dos resultados descritos pudemos constatar que as atividades desenvolvidas por meio da "Oficina de Vivência Corporal", foram muito bem recebidas pelos sujeitos que participaram das mesmas. Avaliamos como positivo o retorno das repercussões obtidas por meio da presente pesquisa, o que nos permitiu desenvolver experiências, avaliar e sistematizar um conjunto de práticas destinados à vivências individuais e grupais aplicadas ao corpo de quem cuida do corpo do outro.

\section{CONSIDERAÇÕES FINAIS}

A experiência foi significante, pois os métodos utilizados nessa atividade pedagógica serviram de experiência pessoal e de contribuição para organizar uma fórmula de atividade em grupo envolvendo movimento, massagem e relaxação, onde conseguimos tratar de assuntos específicos de uma categoria profissional, construir um espaço ou um campo para a tomada de consciência do corpo que pode criar um sistema novo de ligações e de transações que se estabelecem entre elementos da vivência.
Os resultados obtidos através deste estudo suplantou nossas expectativas e certamente contribuirá para com a "Oficina de Vivência Corporal". Também revelou que estamos no caminho certo, proporcionando aos alunos de Enfermagem experiências no campo da consciência corporal, alívio do estresse e percepção do outro, que certamente repercutirá nos procedimentos de cuidar prestados ao paciente.

\section{REFERÊNCIAS BIBLIOGRÁFICAS}

(1) Leopardi MT. Entre a moral e a técnica: ambigüidades do cuidado de enfermagem. Florianópolis: Editora da UFSC; 1994.

(2) Waldow VR. Cuidado humano: o resgate necessário. Porto Alegre: Sagra Luzzatto; 1998.

(3) Patrício ZM. O cuidar/cuidado com famílias de adolescentes grávidas: aplicação de um marco conceitual de enfoque sócio - cultural. In: Elsen I, Penna CMM, Altholff CR, Bub LIR, Patricio ZM. Marcos para a prática de enfermagem com famílias. Florianópolis: Editora da UFSC; 1994. p.139 - 160.

(4) Montagu A. Tocar: o significado humano da pele. São Paulo: Summus Editorial; 1988.

(5) Keleman S. O corpo diz sua mente. São Paulo: Summus Editorial; 1996.

(6) Keleman S. Anatomia emocional. São Paulo: Summus Editorial; 1992.

(7) Alexander G. Eutonia: um caminho para percepção corporal. São Paulo: Martins Fontes; 1991.

(8) Vishnivetz B. Eutonia: educação do corpo para o ser. São Paulo: Summus Editorial; 1995.

(9) Sandor P. Técnicas de relaxamento. São Paulo: Vetor; 1982.

(10) Bardin L. Análise de conteúdo. Lisboa - Portugal: Edições 70; 1995.

(11) Schustz JH. O treinamento autógeno: auto-relaxação concentrativa e exposição clínico-prática. São Paulo: Mestre Jou; 1978.

(12) Rodrigues MSP, Leopardi MT. O método de análise de conteúdo: uma versão para enfermeiros. Fortaleza: Fundação Cearense de Pesquisa e Cultura; 1999.

(13) Lüdke M, André MDEA. Pesquisa em educação: abordagens qualitativas. São Paulo: EPU; 1986.

(14) Minayo MCS. O desafio do conhecimento - pesquisa qualitativa em saúde. São Paulo: HUCITEC ABRASCO; 1914

(15) Rudio FV. Introdução ao projeto de pesquisa científica. Petrópolis, RJ: Vozes; 1986.

(16) Chizzotti A. Pesquisa em ciências humanas e sociais. São Paulo: Cortez; 1991.

(17) Fonseca V. Uma abordagem neuropsicológica à somatognosia. Infanto. 1997; 5(1): 4-14.

\section{Artigo recebido em 30/06/00 \\ Artigo aprovado em 14/12101}

